\title{
LXVII. On the detached colorimeter, and on colorimetry
}

\author{
Edmund J. Mills D.Sc. F.R.S.
}

To cite this article: Edmund J. Mills D.Sc. F.R.S. (1879) LXVII. On the detached colorimeter, and on colorimetry, Philosophical Magazine Series 5, 7:45, 437-441, DOI: 10.1080/14786447908639638

To link to this article: http://dx.doi.org/10.1080/14786447908639638

曲 Published online: 13 May 2009.

Submit your article to this journal $[\pi$

Џ Article views: 3

Q View related articles $₫$ 
the differential coefficient $\frac{d \mathrm{~T}}{d t}$; and in that case the potential energy $\mathrm{T}$ of the liquid does change ; consequently the retarding force in question above is not augmented then, as in the general case; and for this reason the diameter of the sheet must be greater than usual.

This curious result of my theory is fully confirmed by Savart's experiments. With an orifice of 3 millims. the aureoled open sheet had a diameter of 20 centims. when the water was at $1^{\circ} .3 \mathrm{C}$. and was impelled by the pressure of 4.885 metres; while the sheet under the same pressure, but at the temperature of $4^{\circ} \mathrm{C}$., had a diameter of 36 centims.- that is to say, nearly four times the surface. In my opinion, this considerable difference simply proceeds from the potential energy $\mathrm{T}$ of the water at its maximum of density having a maximum value, so that $\frac{d \mathrm{~T}}{d t}=0$.

(e) If the foregoing conclusion is accurate, in operating with water at $10^{\circ} \mathrm{C}$., for example, a cooling must be found to take place in the sheet, while, on the contrary, if the water is at first at, say, $1^{\circ} \cdot 3$, it must grow warmer in spreading.

$(f)$ Since, as I have proved in a previous investigation, to every thermal variation a difference of electric potential corresponds, the spreading-out of water at its maximum of density into a sheet cannot give rise to a thermoelectric current, provided the temperature in it does not change ; on the contrary, the formation of the liquid sheet must be accompanied by a current in one direction if the initial temperature of the liquid be above $4^{\circ} \cdot 5$, and in the opposite direction if it be below $4^{\circ} .5$.

I purpose soon to control this important consequence of my formula, If direct observation verify it, I shall therein find a brilliant confirmation of the theory $I$ am seeking to introduce into science.

LXVII. On the Detached Colorimeter, and on Colorimetry. By Edmund J. Milis, D.Sc., F.R.S., "Young" Professor of Technical Chemistry in Anderson's College, Glasgow*.

THE ordinary detached colorimeter consists of two equal 1 test-tubes. mounted on feet. It is a simple, but in many respects an imperfect, instrument. Several of its defects were removed by the Portable Colorimetert, which has been found to work well in the majority of cases. Room, however, has

* Communicated by the Author.

$\dagger$ Proc. Phil. Soc. Glasgow, x. p. 310. 
still been left for an apparatus from which leakage at the bottom is impossible, and in which, as in the common detached colorimeter, the liquid comes into contact only with glass.

The new detached colorimeter* is made in two pieces, alike in every respect; one of these is represented in the subjoined figure:-It consists of a stout glass tube having a broad flat foot, and graduated into 100 equal parts ; its capacity at the upper part is about 120 cubic centims. On the top of this is a loosely fitting brass cap, prolonged downwards so as to cover and shade the surface of the liquid, thereby preventing the appearance of a dark meniscus. The surface of the liquid is only visible sideways through the little aperture $a$, cut out for that purpose. The cap is perforated centrally; and a short tube $t$ rises from the perforation. This tube is soldered laterally to a narrower one $t^{\prime}$, and this again to a small block $b$, from which rises a spring carrying another small block $b^{\prime}$. The tube $t^{\prime}$ has, cemented into it, a glass tube $u$, which pásses straight downwards, and reappears below the flat surface of the cap, its end amply clearing that surface. This tube is coned outwards at its upper extremity, but is left plain below. Through it there passes, with just sufficient room to move, the rod $r r$, bent below twice at right angles,

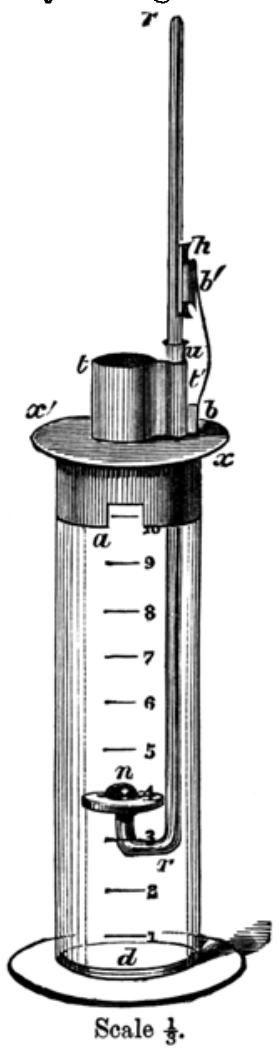
so as to carry a flat circular "opal" glass disk, to which it is attached by fusion. These disks are turned in the lathe: their surfaces should be polished free from scratches, and their edges show no bevel. The rod is prevented from falling by the easy pressure of the little half-tube $h$, carried by the block $b^{\prime}$. When the thumb and fore finger are lightly pressed on $x$ and $x^{\prime}$, the rod can be readily moved up and down, and will then stay in any position in which it may have been left. It is convenient to cone outwards the half-tube $h$ at both its ends; but only traces of liquid ever reach this spot.

The instrument has two accessories which are of considerable service. These consist (1) of a pair of glass disks, $d$,

* The instrument has been made for me by Messrs. Cetti and Co., Brooke Street, Holborn. 
lying at the bottom of the tube, one having a suitable red, the other a green colour; there is thus obtained a black ground, on which the opal disk is always seen through $t$. An annulus of deeper tint than a given observed colour would otherwise surround the opal disk, and tend to confuse the determination. It is an advantage at times to ase other colours, and even to cover the opal disk with a plate of coloured glass. The other accessory is (2) a black hemispherical button $n$. This lies loosely on the opal disk, as shown in the figure. It is used in the estimation of turbidities (i. e. precipitates), by lowering it until its point just disappears.

In taking readings, the position of the flat surface with regard to the scale is always the object to be ascertained; and this can be done, as is the case with Erdmann's float, so as entirely to avoid parallax. The level of the liquid's surface is afterwards taken; and the difference between the two readings is the depth required; but if the button be used, the height of the button must be subtracted from that difference.

It is of course obvious that any upward or downward movement of the rod must alter somewhat the level of the surface of the liquid. For small variations thus produced (as, for example, by a depression of two or three divisions) no correction need be made. For larger variations, a factor is easily found by experiment; it is probably the same in every specimen of the instrument, viz. nearly 0.015 division for every division the rod is moved. This correction is perhaps rather better than direct reading.

\section{Remarks on Colorimetry.}

The colorimeter has been of late years more extensively used than formerly; but it would probably be much more widely employed if its service were better understood. Thus, for example, a red liquid like a solution of magenta is admirably suited for colorimetric measurement, it having a tint to which the eye readily adapts itself. On the other hand, it is rare to find any one who can accurately estimate yellow. Something thus depends on the eye, and on the employment of the same eye. It must also be borne in mind that very few liquids will stand a dilution of over 20 per cent. without undergoing chemical change. Thus, a very weak solution of magenta differs in actual colour from a strong one. Hence it is obviously necessary to use the first determination as a mere approximation; and, on that as a basis, to alter the strengths of the standard and trial liquid to equality. A second determination is now made, and a still closer approximation obtained 
by its means-this process being repeated until there is only a difference of a division or two between the two liquids.

The second approximation will in general be found sufficiently exact. All dilutions should as far as possible have the same age. With regard to the standard tint selected, the operator has in this colorimeter the means of varying his standard to any extent by shifting one opal disk; he can thus work at the particular depth of tint which he tinds most suitable to his own eye. Steady accuracy in any particular measurement can generally be obtained by at most a few days' practice.

Turbidities.-In connexion with the Portable Colorimeter, I pointed out* that a black or coloured disk, lowered through a turbid liquid, eventually vanishes, and that the depth at which disappearance takes place is a measure of the amount of turbidity present. In this way, for example, it is easy to estimate the amount of water added to milk. It is obvious, however, that this method admits of quantitative extension to all sorts of precipitates, provided we can find a suitable medium to ensure their suspension as a turbidity, and not in the aggregated state, during a svitable time.

The suspensory liquid I now employ consists of $100 \mathrm{grms}$. of gelatine, 100 grms. at most of glacial acetate (" acetic acid"), and 1 grm. of saiicylate ("salicylic acid") dissolved in a litre of distilled water: this is clarified with a little white of egg, and filtered hot. It remains permanently liquid in the cold, and does not putrefy. It may, if desired, be charged with any special reagent (baric chloride for instance): a volume of the mixture can then be added to a volume of a very weak standard sulphate, and also to a volume of sulphate of unknown strength; by depressing the black buttons, the colorimeters determine the relation between the two. The reacting bodies should in such cases be the same; thus, hydric sulphate should not be compared against potassic sulphate. The key to success in colorimetry is, in fact, equality of condition.

If the precipitant should be alkaline, or an alkaltne carbonate, the gelatine solution should first be neutralized and then mixed with more alkali or carbonate. Such solutions as aqueous magnesic chloride and zinc sulphate can then be added, the whole instantly well shaken, and the result compared with a standard effect in the other tube.

Lime can be determined by adding ammonia and ammonic oxalate to the suspensory liquid, and then a weak solution of calcic salt.

There is probably no substance incapable of suspension for * Loc. cit. p. 312. 
more than half an hour-a period sufficient for thirty comparisons; and most precipitates will refuse to fall for hours, sometimes for days, together. Traces of argentic chloride will remain unprecipitated in this liquid for months. The operator has therefore only to select such a strength of standard precipitate as shall give him not too great an amount to suspend, and an opacity equal to about fifty scale-divisions. If the substance precipitated should be soluble in the solution of gelatine, that solution should be saturated, before use, with the precipitate in question.

The estimation of turbidities will donbtless prove of much value in water-analysis, in field work, in the raluation of pharmaceutical extracts precipitable by water (hitherto an unapproachable subject), in watching the variations in composition of well-water for brewing-purposes, in the systematic examination of the atmosphere's impurities, in Eggertz's carbon process, and in many similar lines of research.

The colorimeter is an instrument admirably adapted for use in comparatively unskilled hands, and especially in those industrial analyses where one class of product is constantly tested by a single person.

\section{Proceedings of Learned Societies.}

\section{GEOLOGICAL SOCIETY.}

[Continued from p. 370.]

April 30.-Henry Clifton Sorby, Esq., F.R.S., President, in the Chair.

THE following communications were read:-

1. "A Contribution to the History of Mineral Veins." By John Arthur Phillips, Esq., F.G.S.

In this paper the author described the phenomena of the deposition of minerals from the water anc steam of hot springs, as illustrated in the Californian region, referring especially to a great "sulphur bank" in Lake County, to the steamboat springs in the State of Nerada, and to the great Comstock lode. He noticed the formation of deposits of silica, both amorphous and crystalline, enclosing other minerals, especially cinnabar and gold, and in some cases forming true mineral veins. The erystalline silica formed contains liquid-cavities, and exhibits the usual characteristics of ordinary quartz. In the great Comstock lode, which is worked for gold and silver, the mines have now reached a considerable depth, some as much as 2660 feet. The water in these mines was always at a rather high temperature; but now in the deepest mines it issues at a temperature of $157^{\circ} \mathrm{Fahr}$. It is estimated that at least $4,200,000$ tons of water are now annually pumped from the workings; 